\title{
Candidate gene analysis of thyroid hormone receptors in metamorphosing vs. nonmetamorphosing salamanders
}

\author{
S. RANDAL VOSS*†, H. BRADLEY SHAFFER $\ddagger$, JESSICA TAYLOR \\ RACHID SAFI§ \& VINCENT LAUDET§ \\ $\dagger$ Department of Biology, Colorado State University, Ft. Collins, CO 80523, U.S.A., $₫$ Section of Evolution and \\ Ecology and Center for Population Biology, University of California, Davis, CA 95616, U.S.A. and \\ §UMR 49 du CNRS, Ecole Normale Superieure de Lyon, 46 Allee d'Italie, 69364 Lyon Cedex 07 France
}

\begin{abstract}
We used two different experimental approaches to test the hypothesis that thyroid hormone receptor (TR) variation is associated with alternate life cycles modes in ambystomatid salamanders. In the first experiment, the inheritance of $T R \alpha$ and $T R \beta$ genotypes was determined for metamorphic and non metamorphic offspring from backcrosses between Ambystoma mexicanum (an obligate metamorphicfailure species) and metamorphic $\mathrm{F}_{1}$ hybrids (A. mexicanum $\times$ A. tigrinum tigrinum). The segregation of TR genotype was independent of the expression of life cycle mode phenotype, and neither TR locus was linked to DNA markers that flank a major-effect locus for life cycle mode. In the second experiment, a portion of the ligand-binding domain of $T R \alpha$ and $T R \beta$ was cloned and sequenced for DNA samples from 14 different ambystomatid salamander populations, including obligate metamorphic, facultative metamorphic, and obligate metamorphic-failure taxa. Nucleotide sequence variation was found for both $T R \alpha$ and $T R \beta$, with several nonsynonomous substitutions that presumably code for nonconservative amino acid replacements. However, no general relationship was found between TR allelic variation and life cycle mode among populations or species. These data do not implicate TRs as candidate loci involved in the current maintenance or past evolution of alternate life cycle modes in members of the tiger salamander complex.
\end{abstract}

Keywords: Ambystoma, metamorphic failure, metamorphosis, thyroid hormone, thyroid hormone receptor.

\section{Introduction}

Post-embryonic development often involves wholesale modifications of organismal form and function, a process described in general terms as metamorphosis. For many invertebrate and vertebrate species, metamorphosis entails a large suite of character changes necessary for an ecologically important transition during the life cycle (Wilbur, 1980). Interestingly, the entire ensemble of character changes that occur at metamorphosis are regulated hierarchically by relatively few hormones, with ecdysteroid and thyroid hormone as the primary regulators of insect and amphibian metamorphosis, respectively (Cherbas and Cherbas, 1996). These hormones are thought to specify metamorphic character changes via interactions with nuclear receptors that

\footnotetext{
*Correspondence. E-mail: srvoss@lamar.colostate.edu
}

(C) 2000 The Genetical Society of Great Britain. regulate tissue-specific patterns of gene expression (Gronemeyer and Laudet, 1995). In this respect, nuclear hormone receptors play an important, primary role in regulating metamorphosis and represent potential candidate genes responsible for ecologically and evolutionarily important variation in metamorphic response.

Thyroid hormone (TH) and thyroid hormone receptors (TRs) are known to be essential for amphibian metamorphosis. Both bioactive forms of thyroid hormone (tetraiodithyronine or $\mathrm{T} 4$, and triiodithyronine, or T3) can induce precocious metamorphosis in many amphibians, and increasing or maximal levels of $\mathrm{TH}$ coincide with major character changes during natural metamorphosis (Dodd and Dodd, 1976). Two different thyroid hormone receptor genes also increase in number during the larval period, with maximal and sustained levels of $T R \alpha$ mRNA achieved during premetamorphosis (Baker and Tata, 1990; Yaoita and Brown, 1990; Kawahara et al., 1991). In contrast, TR $\beta$ mRNA 
expression is low during premetamorphosis, but increases during prometamorphosis, apparently as a result of autoinduction of $T R \beta$ transcription by rising levels of TRs (Machuca et al., 1995). The various morphological changes that occur during these different phases of metamorphosis may be regulated by tissue-specific levels of TH, TR, and retinoic acid receptors (Shi et al., 1996).

Thyroid hormone receptors have both ligand- and DNA-binding domains, and therefore act as transcriptional regulators by binding to specific thyroid hormone response elements in the promotor regions of target genes (Evans, 1988; Gronemeyer and Laudet, 1995). In general, unliganded TRs act as transcriptional repressors and liganded TRs are transcriptional activators, although point mutations in TRs can lead to a failure to repress or activate certain genes (Refetoff et al., 1993). Many different amino acid replacements within the ligand binding domain are associated with variable, physiological responses to thyroid hormone. In particular, mutations within hydrophobic amino acid repeats (heptads) of this region may affect ligand binding, receptor dimerization, and interactions with corepressors (Forman et al., 1989; Collingwood et al., 1994, 1997; Wagner et al., 1995; Yoh et al., 1997).

Variation in physiological response to thyroid hormone may have played an important role in vertebrate developmental evolution (Frieden, 1981; Hanken et al., 1997). For example, many species of salamander fail to undergo a complete metamorphosis (a condition we refer to as metamorphic failure, but which is often referred to as paedomorphosis and neoteny; see Gould, 1977; Reilly et al., 1996) and therefore retain many larval characters throughout the life cycle. In these cases, the metamorphic-failure life cycle has apparently evolved as a result of mutations to genes that alter thyroid hormone induction of metamorphosis (Shaffer and Voss, 1996). Several different candidate genes, including TRs, have been implicated from classical physiological experiments of salamanders that fail to metamorphose. The possible importance of mutations in TR genes has gained recent support from an analysis of two closely related ambystomatid species, where amino acid differences in the ligand-binding domains of $T R \alpha$ were found between the obligate metamorphic-failure species Ambystoma mexicanum and the obligate metamorph A. tigrinum tigrinum (Safi et al., 1997).

Given the possible importance of amino acid substitutions on $T R \alpha$ function during metamorphosis in $A$. mexicanum (as well as other mutations that may be in linkage disequilibrium with specific $T R \alpha$ and $T R \beta$ alleles), we tested the hypothesis that TR variation is associated with expression of life cycle mode in ambystomatid salamanders. This hypothesis was tested in two different experiments. First, we examined $T R \alpha$ and $T R \beta$ for linkage to DNA markers that flank a major-effect locus for metamorphic failure in $A$. mexicanum (Voss and Shaffer, 1997). If $T R \alpha$ or $T R \beta$ are linked to these flanking DNA markers, this would be consistent with a causal relationship between TRs and metamorphic failure that could be investigated in subsequent studies of gene structure and function. Failure to identify a linkage relationship would exclude these genes as major-effect loci underlying expression of metamorphic failure in $A$. mexicanum. In the second experiment, $T R \alpha$ and $T R \beta$ allelic variation was assessed within and among natural populations of Mexican ambystomatid salamanders that vary in life cycle mode. During the last few million years, three life cycle modes have evolved repeatedly and independently among Mexican ambystomatid populations and species: (i) obligate metamorphosis; (ii) obligate metamorphic failure; and (iii) facultative metamorphosis (metamorphosis or metamorphic failure) (Shaffer and Voss, 1996). Under the hypothesis that mutations of TRs have been important in the recent evolutionary diversification of this group, specific TR alleles may be uniquely associated with populations and species that exhibit the same life cycle mode. Also, because TRs may be evolving differentially in obligate metamorphic-failure species, and because the crystal structure of the ligand-binding domain of $T R \alpha$ has been described (Wagner et al., 1995), we also examined primary and secondary gene structure of $T R \alpha$ and $T R \beta$ alleles for functionally important mutations that might be associated with life cycle mode in natural populations.

\section{Materials and methods}

\section{Experiment 1}

The crossing strategy and phenotypic segregation analysis were described previously (Voss, 1995). Briefly, an interspecific cross was made between an obligate metamorphic species (female, A. tigrinum tigrinum from a population near Nashville, TN: Charles D. Sullivan Co.) and an obligate metamorphic-failure species (male, A. mexicanum from Indiana Axolotl Colony). Two $\mathrm{F}_{1}$ male hybrids were then backcrossed to a female A. mexicanum to produce second-generation populations in which alternate life cycle modes were segregating. Individuals were scored as metamorphs if external gills were completely resorbed within 450 days of hatching.

DNA was isolated from 108 backcross offspring (Voss, 1995) and genotyped for $T R \alpha$ and $T R \beta$. TR genes were amplified by PCR using the following primers: $T R \alpha$ forward = 5'-TCCTGACAGTGAGACGCTG-3', TR $\alpha$ reverse $=5^{\prime}$-TAGGGCCACTTCGGTGTCATC-3';R $\beta$ 
forward $=5^{\prime}$-CCCGGAAAGCAAAACCTT- $3^{\prime}, \quad T R \beta$ reverse $=5^{\prime}$-TATCATCCAGGTTAAATGAC- $3^{\prime}$. The $T R \alpha$ and $T R \beta$ primers flank 150 and 136 bp sequences, respectively, of the ligand-binding domains, and were designed from cloned sequences from both $A$. mexicanum and A. tigrinum (Safi et al., 1997). PCR conditions for both TR sequences were $200 \mathrm{ng}$ DNA, $0.25 \mathrm{Mm}$ each primer, $1 \mathrm{mM} \mathrm{MgCl}_{2}$, $0.1 \mathrm{U}$ Taq polymerase, $200 \mu \mathrm{M}$ each of dATP, dTTP, dCTP, dGTP, and $1 \times$ PCR buffer $(10 \mathrm{~mm}$ Tris- $\mathrm{HCl}, \mathrm{pH} 8.3,50 \mathrm{~mm} \mathrm{KCl})$ at a total reaction volume of $25 \mu \mathrm{L}$. The PCR cycling parameters were: 4 min initial melt at $94^{\circ} \mathrm{C} ; 30$ cycles of $1 \mathrm{~min}$ at $94^{\circ} \mathrm{C}, 1.5 \mathrm{~min}$ at $60^{\circ} \mathrm{C}(T R \alpha)$ or $1.5 \mathrm{~min}$ at $57^{\circ} \mathrm{C}(T R \beta)$; 1 cycle for $5 \mathrm{~min}$ at $72^{\circ} \mathrm{C}$.

$T R \alpha$ alleles were scored as Single-Stranded Confirmation Polymorphisms [SSCPs (Orita et al., 1989)]. Approximately $8 \mu \mathrm{L}$ from each $T R \alpha$ PCR amplification was mixed with $2.5 \mu \mathrm{L}$ of formamide loading buffer ( $98 \%$ formamide, $1 \mathrm{~m} \mathrm{NaOH}$, bromophenol blue, cyanol green) and denatured for $4 \mathrm{~min}$ at $94^{\circ} \mathrm{C}$. Denatured samples were immediately placed on ice and then loaded into $16 \mathrm{~cm} \times 20 \mathrm{~cm}, 6 \%$ polyacrylamide gels (Hiss et al., 1994). Electrophoresis was at $350 \mathrm{~V}$ for $2.5 \mathrm{~h}$ at $17^{\circ} \mathrm{C}$ using $0.6 \times \mathrm{TBE}$ buffer. Gels were then stained in ethidium bromide and visualized under UV light.

$T R \beta$ alleles were scored as restriction fragment length polymorphisms. The restriction enzyme Xho-I recognizes a single cut-site in the $T R \beta$ allele of the P1 A.t. tigrinum, that is absent in $A$. mexicanum. Approximately $7 \mu \mathrm{L}$ from each $T R \beta$ PCR amplification was mixed with $1 \mu \mathrm{L}$ of $10 \times$ enzyme reaction buffer and $2.5 \mathrm{U}$ Xho-I. After an overnight incubation at $37^{\circ} \mathrm{C}$, restriction digests were loaded into $15 \%$ polyacrylamide gels $(16 \mathrm{~cm} \times 20 \mathrm{~cm})$. Electrophoresis was at $150 \mathrm{~V}$ for $5 \mathrm{~h}$ at room temperature using $1 \times \mathrm{TBE}$ buffer, and gels were stained in ethidium bromide and visualized under UV light.

Two genotypes are expected to segregate randomly for each locus in a backcross design: a heterozygous and a homozygous genotype. The segregation of TR genotypes was compared to the inheritance of life cycle mode phenotype (metamorphic and metamorphic failure) using a $\chi^{2}$ test. Also, a subset of backcross offspring $(N=79)$ were used to test $\operatorname{TR} \alpha$ and $\operatorname{TR} \beta$ for linkage to DNA markers that flank a major-effect gene underlying expression of life cycle mode (Voss and Shaffer, 1997). Linkage between TR genes and flanking DNA markers was evaluated by calculating LOD scores (Ott, 1991; equation 3.2, p. 41). Statistical significance for linkage was evaluated by comparing calculated LOD scores to a threshold value of $L O D=2.3$ (200:1 odds in favour of linkage), with values exceeding $\mathrm{LOD}=2.3$ indicating a statistically significant association between the flanking markers and TR genotype.

\section{Experiment 2}

$T R \alpha$ and $T R \beta$ allelic variation were determined for a subset of DNA samples from Shaffer and McKnight (1996), a study that examined mitochondrial DNA (mtDNA) variation among ambystomatid (A. tigrinum complex) populations and species, including all know metamorphic-failure populations from Mexico. Table 1 shows the population origin of these samples, as well as the life cycle mode that characterizes each of these populations (life cycle modes were confirmed with field surveys in Mexico to document the presence of transforming or paedomorphic adults; Shaffer, 1984). A single individual was analyzed from all but population 72 , where we also included a captive-bred individual from our breeding colony (72b). TR $\alpha$ and $T R \beta$ alleles were amplified using the primers and PCR conditions described above, and then ligated into TA-vectors (Invitrogen). TA-vectors were transformed into either JM109 or DH5- $\alpha$ cells, and plated on LB ampicillin plates. Positive clones were sequenced in both directions using M13 primers and an automated sequencer (ABI 377). Unique TR alleles were verified by sequencing a second clone. Ambystomatid TR sequences were aligned by eye and compared to other vertebrate TR sequences in GenBank (Release 104.0).

Table 1 Thyroid hormone receptor allelic variation from populations of Mexican ambystomatids that are characterized by different life cycle modes. Population ID is described in Shaffer and McKnight (1996)

\begin{tabular}{lcccc}
\hline Species & $\begin{array}{c}\text { Population } \\
\text { ID }\end{array}$ & $\begin{array}{c}\text { Life cycle } \\
\text { mode }\end{array}$ & $\begin{array}{c}T R-\alpha \\
\text { ID }\end{array}$ & $\begin{array}{c}T R-\beta \\
\text { ID }\end{array}$ \\
\hline A. velasci & 46 & $\mathrm{M}$ & 1.1 & 2.1 \\
A. velasci & 48 & $\mathrm{M}$ & 1.1 & 1.1 \\
A. rosaceum & 51 & $\mathrm{M}$ & 3.1 & 1.1 \\
A. velasci & 53 & $\mathrm{M}$ & 1.1 & 1.1 \\
A. andersoni & 55 & $\mathrm{MF}$ & 1.2 & 1.1 \\
A. dumerilli & 56 & $\mathrm{MF}$ & 1.3 & 1.1 \\
A. amblycephalum & 58 & $\mathrm{~F}$ & 1.4 & 1.1 \\
A. ordinarium & 60 & $\mathrm{~F}$ & 4.1 & 1.1 \\
A. granulosum & 61 & $\mathrm{M}$ & 1.1 & 3.1 \\
A. mexicanum & 68 & $\mathrm{MF}$ & 1.1 & 1.1 \\
A. velasci & 70 & $\mathrm{~F}$ & 1.1 & 1.1 \\
A. velasci & 71 & $\mathrm{M}$ & 1.1 & 1.1 \\
A. velasci & $72 \mathrm{a}$ & $\mathrm{MF}$ & 2.1 & 1.1 \\
A. velasci & $72 \mathrm{~b}$ & $\mathrm{MF}$ & 1.5 & 1.1 \\
A. velasci & 75 & $\mathrm{M}$ & 2.1 & 1.1 \\
\hline
\end{tabular}

$\mathrm{M}$, metamorphosis; MF, metamorphic failure; $\mathrm{F}$, facultative (M and MF).

Alleles encoding different amino acid sequences differ in the prefix of their ID, and, for $T R-\alpha 1$ alleles, the suffixes differentiate five alleles showing synonymous variation. 


\section{Results}

\section{Experiment 1}

The genotypic scores for $T R \alpha$ and $T R \beta$ are shown in Table 2 . The segregation of TR genotype was independent of the expression of life cycle mode (TR $\alpha: \chi^{2}=3.306$, $P=0.069 ; T R \beta: \chi^{2}=0.043, P=0.836$ ). The marginally nonsignificant $\chi^{2}$ value for $T R \alpha$ appeared to reflect a tendency for metamorphs to score as homozygotes (A. mexicanum genotype) and metamorphic failure to score as heterozygotes (the $F_{1}$ genotype; all $F_{1}$ 's underwent metamorphosis, Voss, 1995). This potential association is the opposite of the pattern expected if $T R \alpha$ were a candidate for the life cycle mode locus, which is primarily determined by a major recessive gene (Voss and Shaffer, 1997).

The TR loci were also tested for linkage to DNA markers that have been shown to flank the major-effect locus underlying expression of life cycle mode in these backcrosses (Voss and Shaffer, 1997). The LOD scores that were calculated for each pairwise linkage test were all very low and nonsignificant (Table 3 ). Thus, the data suggest that $T R \alpha$ and $T R \beta$ are unlinked, and that neither TR locus is linked to the DNA markers that flank the life cycle mode locus. This result is consistent with the $\chi^{2}$ test described above; taken together, these data do not implicate either TR locus as a major-effect locus underlying expression of life cycle mode in A. mexicanum.

\section{Experiment 2}

Allelic variation was found among taxa for both $T R \alpha$ and $T R \beta$. Here we introduce a prefix/suffix nomenclature to describe $T R \alpha$ and $T R \beta$ allelic variation, with the prefix number referencing nucleotide sequences that presumably code for different amino acid sequence, and the suffix number referencing different nucleotide sequences that presumably code for the same amino acid sequence. A total of eight $T R \alpha$ alleles and three $T R \beta$ alleles were identified, with $T R \alpha 1.1$ (freq. $=0.47$ ) and $T R \beta 1.1$ (freq. $=0.87$ ) observed in the majority of the populations (Table 1). TR $\alpha 1$ alleles were observed among metamorphic, facultative, and metamorphic-failure populations, with $T R \alpha 1.2, T R \alpha 1.3, T R \alpha 1.5$, and $T R \alpha 1.4$ representing unique alleles from three different metamorphic-failure and one facultative population, respectively. Similarly, $T R \alpha 2.1$ was identified from two $A$. velasci populations that are each characterized by a different life cycle mode. Thus, overall, there was no relationship between $T R \alpha$ genotype and life cycle mode phenotype.

Similarly, no relationship was found when comparing allelic variation in $T R \beta$ with population/species-specific
Table 2 Life cycle mode (LCM), phenotypic and TR genotypic frequencies from backcrosses

\begin{tabular}{lccc}
\hline \multirow{2}{*}{$\begin{array}{l}\text { Phenotype } \\
\text { LCM }\end{array}$} & \multicolumn{2}{c}{ TR genotype } & \\
\cline { 2 - 3 } & $T R-\alpha$ & $T R-\beta$ & Frequency \\
\hline M & 0 & 0 & 16 \\
M & 0 & 1 & 23 \\
M & 1 & 0 & 10 \\
M & 1 & 1 & 15 \\
MF & 0 & 0 & 8 \\
MF & 0 & 1 & 11 \\
MF & 1 & 0 & 16 \\
MF & 1 & 1 & 16 \\
\hline
\end{tabular}

M, metamorphosis; MF, metamorphic failure.

For TR genotypes: 1, heterozygote; 0 , homozygote.

Table 3 LOD scores for pairwise linkage tests between TR loci and AFLP markers that flank a major effect locus for life cycle mode (see Voss and Shaffer, 1997)

\begin{tabular}{lccc}
\hline Loci tested & $N$ & $k$ & LOD score \\
\hline TR- $\alpha /$ TR- $\beta$ & 79 & 34 & 0.334 \\
TR- $\alpha /$ AFLP34.5 & 77 & 44 & 0.342 \\
TR- $\alpha /$ AFLP32.17 & 78 & 42 & 0.100 \\
TR- $\alpha /$ AFLP11.7 & 77 & 37 & 0.025 \\
TR- $\beta /$ AFLP34.5 & 77 & 38 & 0.003 \\
TR- $\beta /$ AFLP32.17 & 78 & 41 & 0.045 \\
TR- $\beta /$ AFLP11.7 & 77 & 43 & 0.229 \\
\hline
\end{tabular}

Sample sizes $(N)$ varied because of missing data.

$k$, number of observed recombinant genotypes for the tested loci. A threshold of $\mathrm{LOD}=2.3$ was used to evaluate significance.

life cycle mode. The TR $\beta 1$ allele was identified from metamorphic, facultative, and metamorphic-failure populations, with $T R \beta 2$ and $T R \beta 3$ representing unique alleles from two different metamorphic populations. Although unique $T R \alpha$ alleles were more commonly associated with metamorphic failure populations (three of six), the two unique $T R \beta$ alleles were associated with metamorphic populations. Overall, these data indicate no general relationship between life cycle mode and TR allelic variation among populations or species.

High sequence similarity was found among the alleles of each TR gene; pairwise differences ranged from 1-5 nucleotide substitutions (Fig. 1). Presumably, four of the $T R \alpha$ alleles and three $T R \beta$ alleles specify different, yet functional amino acid sequences. In comparison to TRs from several more distantly related metamorphicfailure salamander taxa and to human TRs, amino acid sequence similarity is very high to the Ambystoma sequences reported here (Fig. 2). For example, $T R \alpha$ is 
Fig. 1 Alignment of DNA sequences for a portion of the ligand-binding domain of thyroid hormone receptors $\alpha$ and $\beta$ from Mexican ambystomatid salamanders. Dashes indicate undetermined sequences and points indicate nucleotides identical to the $T R \alpha 1.1$ sequence.
1

40

80

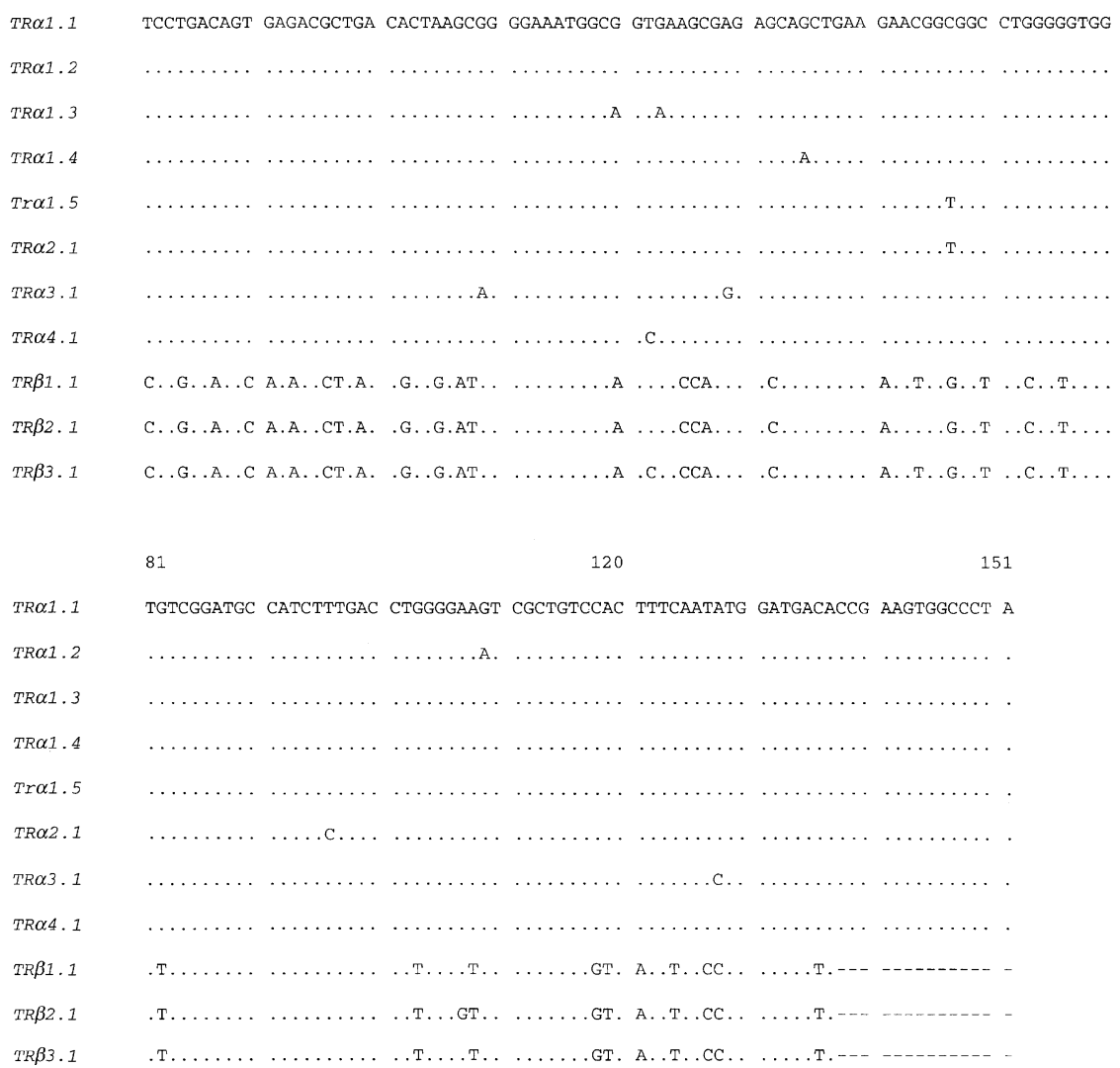

85-95\% similar comparing human to Ambystoma, and $T R \beta$ shows $85-91 \%$ sequence similarity for this same comparison. Several amino acid substitutions were either observed uniquely among all ambystomatid sequences or among metamorphic-failure salamanders in general. Three of these substitutions $(T R \alpha$ : Ala/Thr, 40; TR $\beta$ : Glu/Lys, 4; and Gly/Asp, 17) are presumably nonconservative, because they involve amino acids with different physicochemical properties (Li, 1997). Unique, nonconservative amino acid substitutions were also observed ( $T R \alpha 3$, Ser/Arg, 10; $T R \beta 3$, Val/Ala, 14) within the various heptad repeats, and one amino acid difference was observed at an important hydrophobic position ( $T R \alpha 1 \mathrm{Leu} / \mathrm{Met}, 43)$. This later amino acid substitution, which was recently described for $A$. mexicanum (Safi et al., 1997), is variable among Ambystoma $T R \alpha$ alleles.

However, because none of the $T R \alpha$ alleles are uniquely associated with a facultative or metamorphic-failure life cycle mode, there is little reason to suspect that this amino acid substitution affects receptor function.

\section{Discussion}

The results from our two experiments do not support the hypothesis that TR variation is associated with alternate life cycle modes in ambystomatid salamanders. The results from the first experiment are the most definitive because we directly tested for an association between TR genotype and life cycle mode phenotype using controlled crosses and linkage analysis. Here, our results clearly indicate that neither TR locus is linked to a major-effect locus underlying expression of life cycle mode in backcrosses between the obligate metamorph A. tigrinum tigrinum and the obligate paedomorph A. mexicanum (Voss, 1995; Voss and Shaffer, 1997). Therefore, we conclude that the amino acid substitutions that were recently described for $T R \alpha$ in A. mexicanum (Safi et al., 1997) are not associated with the evolution of metamorphic failure in this species.

The results from the second experiment, although less definitive than the linkage analysis, also support our conclusion that there is no relationship between TR allelic variation and life cycle modes among other Mexican ambystomatids. Here, we extended the TR candidate gene approach to the population/species level to explore the potential role of $\mathrm{TR}$ variation in the evolution of life cycle modes among extent taxa. We view this extension as a logical first step, especially given: (i) the recent origin of the Mexican ambystomatids during the last few million years, and thus the possibility that specific TR alleles may be uniquely

(C) The Genetical Society of Great Britain, Heredity, 85, 107-114. 


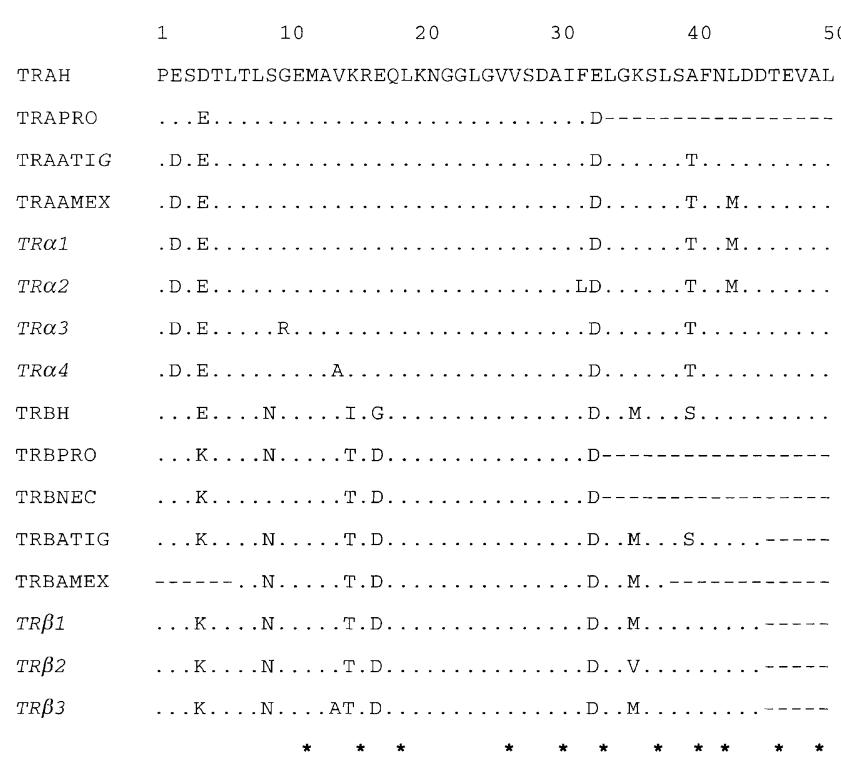

Fig. 2 Amino acid sequences for a portion of the ligandbinding domain of $T R \alpha$ and $T R \beta$ from human (TRAH and TRBH), Ambystoma mexicanum (TRAATIG and TRBATIG), Ambystoma tigrinum tigrinum (TRAATIG and TRBATIG), Proteus anguinus (TRAPRO and TRBPRO), Necturus maculosus (TRBNEC) (Safi et al., 1997), and the $4 T R \alpha$ and $3 T R \beta$ sequences that were identified in this study. The stars correspond to hydrophobic amino acids that are implicated in receptor dimerization (Forman and Samuels, 1990).

associated with populations and species that exhibit the same life cycle mode, and (ii) the paucity of existing TR sequence data from which to evaluate TR sequence evolution and the functionality of TRs in paedomorphic taxa. In general, we found no relationship between TR genotype and life cycle mode phenotype. This is clearly shown by the distribution of the TR $\alpha 1$ and $T R \beta 1$ alleles among taxa differing in all three life cycle modes. Because these taxa represent geographically and phylogenetically distinct lineages (Shaffer and McKnight, 1996; Shaffer and Voss, 1996), it seems likely that alleles very similar to $T R \alpha 1$ and $T R \beta 1$ were present in the ancestral population(s) that gave rise to the extant Mexican ambystomatid fauna. The identification of unique, but functionally equivalent $T R \alpha 1$ alleles for two different metamorphic-failure species suggests that relatively little $T R \alpha$ sequence evolution has occurred since the evolution of these ecologically isolated, metamorphic-failure lineages (Voss and Shaffer, 1997). This pattern of sequence evolution is also suggested by the presence of the $T R \beta 1$ allele among the majority of the Mexican ambystomatids. Overall, this pattern of sequence conservation probably reflects the importance of TH and TRs in regulating other aspects of development that are not related to metamorphosis. Thus, we conclude that the TR ligand-binding domain of Mexican ambystomatids is highly conserved, and there is no evidence for a different evolutionary rate between metamorphic and metamorphic-failure species (Safi et al., 1997).

Of course, we caution that the population/species level results should be viewed as preliminary because we cannot formally exclude the possibility that the observed TR variation is causally associated with life cycle mode. If relatively few base pair substitutions can dramatically alter thyroid hormone responses, then a partial sequence survey of a candidate gene may fail to identify the critical base pair substitutions. Indeed, relatively few amino acid replacements appear to underline the generalized syndrome of resistance to thyroid hormone (Forman et al., 1989; Collingwood et al., 1994, 1997; Yoh et al., 1997), as well as other thyroid hormone axis defects in mammals (Stein et al., 1994; Pohlenz et al., 1997). It is interesting to note that the majority of TR alleles from this study presumably code for different protein sequences, and some of the amino acid substitutions appear to be nonconservative ( $\mathrm{Li}, 1997)$. For example, the $\mathrm{Ser} / \mathrm{Ag} 10$ substitution in $T R \alpha 3$ is also found in $T R \beta$ of patients exhibiting the generalized resistance to thyroid hormone syndrome (Wagner et al., 1995). Given the presumed conservation of function among nuclear receptors, this amino acid substitution (as well as others that were not sampled), which is adjacent to a residue that contacts the carboxylate group of the hormone (Wagner et al., 1995), may affect thyroid hormone responses that underlie metamorphic changes. Indeed, different metamorphic failure species undergo metamorphosis at different rates when induced by $\mathrm{TH}$ treatment, suggesting the possibility of interspecific variation in TR function (Voss, unpubl. data). However, within the limitations of our population/species survey, we reiterate that there are no conspicuous patterns of TR nucleotide sequence variation for Mexican ambystomatids that are associated with variation in metamorphic response.

The candidate gene approach represents a conceptual departure from earlier studies of metamorphic failure in urodeles. Traditionally, the problem of metamorphic failure has been approached from a physiological perspective, with a focus on key endocrine glands and hormones (e.g. Frieden, 1981). Although an association was not found between thyroid hormone receptors and life cycle mode in this study, it is important to realize that in candidate gene analysis a negative result is a positive result because candidate loci are tested and excluded and resources then channeled towards other genes. This is an especially important point because knowledge of all genes that comprise several vertebrate genomes will be a reality within the next 10 years, 
making it possible to systematically identify and test multiple candidate loci for genetic contributions to targeted phenotypes. Moreover, given that these genome data will make it possible to identify homologous chromosomal segments and genes between model organisms, the primary caveat of candidate gene analysis will be eliminated: that is, even though it is not possible in candidate gene analysis to "rule out" that a linked locus and not the candidate gene is contributing genetically to a targeted phenotype, given a knowledge of loci from the targeted chromosome region it will be possible to identify and test other candidate loci. Given this genomics perspective of the future and because homologous chromosomal segments can be identified between genomically well characterized vertebrate models and Ambystoma (Voss, unpubl. data), candidate gene analysis will continue to be an important strategy for testing loci for a genetic contribution to ambystomatid life cycle modes.

\section{Acknowledgments}

We thank Mark McKnight for DNA isolations that were used in the population screen. This work was supported by National Science Foundation Grants BSR-8415756, BSR-9101128 and IBN-9509802.

\section{References}

BAKER, B. S. AND TATA, J. R. 1990. Accumulation of protooncogene $c$-erb- $A$ related transcripts during Xenopus development: association with early acquisition of response to thyroid hormone and estrogen. EMBO J., 9, 879-885.

CHERBAS, P. AND CHERBAS, L. 1996. Molecular aspects of ecdysteroid hormone action. In: Gilbert, L. I., Tata, J. R. and Atkinson, B. G. (eds) Metamorphosis: Postembryonic Reprogramming of Gene Expression in Amphibian and Insect Cells, pp. 175-221. Academic Press, San Diego.

COLLINGWOOD, T. N., ADAMS, M., TONE, Y. AND CHATTERJEE, V. K. K. 1994. Spectrum of transcriptional, dimerization, and dominant negative properties of twenty different mutant thyroid $\beta$ receptors in thyroid hormone resistance syndrome. Mol. Endocrinol., 8, 1262-1277.

COLLINGWOOD, T. N., RAJANAYAGAM, O., ADAMS, M., WAGNER, R., CAVAILleS, V., KALHOVEN, E. ET AL. 1997. A natural transactivation mutation in the thyroid hormone $\beta$ receptor: impaired interaction with putative transcriptional mediators. Proc. Natl. Acad. Sci. U.S.A., 94, 248-253.

DODD, M. H. I. AND DODD, J. M. 1976. The biology of metamorphosis. In: Lofts, B. (ed.) Physiology of Amphibia, pp. 467-599. Academic Press, New York.

EVANS, R. M. 1988. The steroid and thyroid hormone receptor superfamily. Science, 240, 889-895.

FORMAN, B. M. AND SAMUELS, H. H. 1990. Interaction among a subfamily of nuclear hormone receptors: the regulatory zipper model. Mol. Endocrinol., 4, 1293-1301.
FORMAN, B. M., YANG, C., AU, M., CASANOVA, J., GHYSDAEL, J. AND SAMUELS, H. H. 1989. A domain containing leucine zipperlike motifs mediate novel in vivo interactions between the thyroid hormone and retinoic acid receptors. Mol. Endocriol., 3, 1610-1626.

FRIEDEN, E. 1981. The dual role of thyroid hormones in vertebrate development and calorigensis. In: Gilbert, L. I. and Frieden, E. (eds) Metamorphosis: A problem in Developmental Biology, 2nd edn., pp. 545-563. Plenum, New York.

Gould, s. J. 1977. Ontogeny and Phylogeny. Belknap, Cambridge, MA.

GRONEMEYER, H. AND LAUDET, v. 1995. Transcription factors 3: nuclear receptors. Protein Profile, 11, 1173-1308.

HANKEN, J., JENNINGS, D. H. AND OLSSON, L. 1997. Mechanistic basis of life-history evolution in anuran amphibians: direct development. Am. Zool., 37, 160-171.

HISS, R. H., NORRIS, D. E., DIETRICH, C. H., WHITCOMB, R. F., WEST, D. F., Bosio, C. F. ET AL. 1994. Molecular taxonomy using single-strand confirmation polymorphism (SSCP) analysis of mitochondrial ribosomal DNA genes. Insect Mol. Biol., 3, 171-182.

KAWAHARA, A., BAKER, B. AND TATA, J. R. 1991. Developmental and regional expression of thyroid hormone receptor genes during Xenopus metamorphosis. Development, 112, 933942.

LI, w. 1997. Molecular Evolution. Sinauer Associates, Sunderland, MA.

MACHUCA, I., ESSLEMONT, G., FAIRClOUGH, L. AND TATA, J. R. 1995. Analysis of structure and expression of Xenopus thyroid hormone receptor $\beta(\mathrm{xTR} \beta)$ gene to explain its autoinduction. Mol. Endocrinol., 9, 96-107.

ORITA, M., IWAHANA, H., KANAZAWA, H., HAYASHI, K. AND SEKIYA, T. 1989. Detection of polymorphisms of human DNA by gel electrophoresis as single-strand confirmation polymorphisms. Proc. Nat. Acad. Sci. U.S.A., 86, 2766-2770.

OTT, J. 1991. Analysis of Human Genetic Linkage, revised edn. The John Hopkins University Press, Baltimore, MD.

POHLENZ, J., MEdeiros-Neto, G., Gross, J. L., Silveiro, S. P., KNOBEL, M. AND REFETOFF, s. 1997. Hypothyroidism in a Brazilian kindred due to an iodide trapping defect caused by a homozygous mutation in the sodium-iodide symporter gene. Biochem. Biophys. Res. Comm., 240, 488-491.

REFETOFF, S., WEISS, R. E. AND USALA, S. J. 1993. The syndromes of resistance to thyroid hormone. Endocrine Rev., 14, 348-399.

REILly, S. M., WILEY, E. O. AND MEINHARDT, D. J. 1996. An integrative approach to heterochrony: the distinction between interspecific and intraspecific phenomena. Biol. J. Linn. Soc., 60, 119-143.

SAFI, R., BEGUE, A., HANNI, C., STEHELIN, D., TATA, J. R. AND LAUDET, L. 1997. Thyroid hormone genes of neotenic amphibians. J. Mol. Evol., 44, 595-604.

SHAFFER, H. B. 1984. Evolution in a paedomorphic lineage. I. An electrophoretic analysis of the Mexican ambystomatid salamanders. Evolution, 38, 1194-1206.

SHAFFER, H. B. AND McKNIGHT, M. L. 1996. The polytypic species revisited: genetic differentiation and molecular 
phylogenetics of the tiger salamander Ambystoma tigrinum (Amphibia: Caudata) complex. Evolution, 50, 417-433.

SHAFFER, H. B. AND voss, S. R. 1996. Phylogenetic and mechanistic analysis of a developmentally integrated character complex: alternate life history modes in ambystomatid salamanders. Am. Zool., 36, 24-35.

SHI, Y., WONG, J., PUZIANOWSKA-KUZINCKA, M. AND STOLOW, M. A. 1996. Tadpole competence and tissue-specific temporal regulation of amphibian metamorphosis: roles of thyroid hormone and its receptors. Bioessays, 18, 391-399.

STEIN, S. A., OATES, E. L., HALl, C. R., GRUMBLES, R. M., FERNANDEZ, L. M., TAYLOR, N. A. ET AL. 1994. Identification of a point mutation in the thyrotropin receptor of the hyt/ hyt hypothyroid mouse. Mol. Endocrinol., 8, 129-138.

voss, S. R. 1995. Genetic basis of paedomorphosis in the axolotl, Ambystoma mexicanum: a test of the single gene hypothesis. J. Hered., 86, 441-447. voss, S. R. AND SHAFFER, H. B. 1997. Adaptive evolution via a major gene effect: paedomorphosis in the Mexican axolotl. Proc. Natl. Acad. Sci. U.S.A., 94, 14185-14189.

WAGNER, R. L., APriletti, J. W., McGRATH, M. E., WeSt, B. L., BAXTER, J. D. AND FLETTERICK, R. J. 1995. A structural role for hormone in the thyroid hormone receptor. Nature, $\mathbf{3 7 8}$, 690-697.

wilbur, H. M. 1980. Complex life cycles. Ann. Rev. Ecol. Syst., 11, 67-93.

YAOITA, Y. AND BROWN, D. D. 1990. A correlation of thyroid hormone receptor gene expression with amphibian metamorphosis. Genes Dev., 4, 1917-1924.

YOH, S. M., CHATTERJEE, V. K. K. AND PRIVALSKY, M. L. 1997. Thyroid hormone resistance syndrome manifests as an aberrant interaction between mutant $\mathrm{T}_{3}$ receptors and transcriptional corepressors. Mol. Endocrinol., 11, $470-480$. 